\title{
Jogos como gêneros multimodais: análise e elaboração crítica para multiletramentos
}

Games as multimodal genres:

analysis and critical elaboration for multiliteracies

Juegos como géneros multimodales: análisis y elaboración crítica para multiletramentos

\section{* Cynthia Macedo Dias}

Professora na Escola Politécnica de Saúde Joaquim Venâncio (EPSJV/Fiocruz), Rio de Janeiro, Rio de Janeiro, Brasil

cymadi@gmail.com

\section{** Jackeline Lima Farbiarz}

Professora diretora na Pontifícia Universidade Católica do Rio de Janeiro Rio de Janeiro, Rio de Janeiro, Brasil

jackeline@puc-rio.br

Recebido: 19 de outubro de 2018

Aprovado: 20 de novembro de 2018

\section{RESUMO}

O presente artigo traz como hipótese que os jogos são mídias expressivas e multimodais, carregadas de discursos, que podem materializar e suscitar múltiplas construções de sentidos, para além de serem objetos de entretenimento. Objetiva, assim, discutir os jogos enquanto textos multimodais, a fim de propor uma face do "letramento lúdico" que se aproxime da perspectiva de multiletramentos, envolva a leitura crítica e a possibilidade de materialização de discursos de jovens estudantes por meio da criação e modificação de jogos mediada por seus professores. Como percurso metodológico, fundamenta-se nos estudos de gêneros discursivos e multimodalidade, com base em Bakhtin, Miller e Bazerman, Carvalho, Fairclough e Lemke e aplica esse olhar na análise de três versões de um jogo de tabuleiro bastante tradicional e conhecido, o Banco Imobiliário: a versão criada pelo designer Fabio Lopez em 2010, chamada "Bando Imobiliário"; a versão criada pela Estrela em contrato com a Prefeitura do Rio em 2013, "Banco Imobiliário Cidade Olímpica"; e a versão elaborada por professores de escolas públicas municipais e exposta na Cinelândia, um mês após a polêmica levantada pela distribuição do jogo comprado pela Prefeitura nas escolas municipais. $O$ artigo propõe que as reflexões desenvolvidas inspirem a criação e modificação de jogos, no nível verbal, visual ou das regras, a fim de incorporar a polifonia a partir das "vozes" de alunos e professores e possibilitar que regras sociais, discursos e sentidos hegemônicos, muitas vezes naturalizados e ocultos por discursos centrípetos e autoritários, venham à tona e sejam problematizados. 


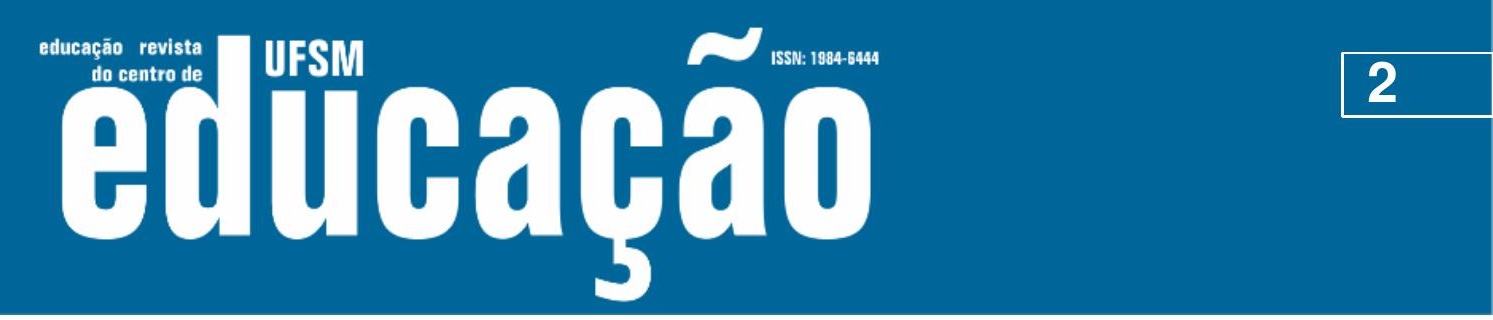

DOI: $10.5902 / 1984644430055$

Palavras-chave: Jogos de tabuleiro; Polifonia; Multiletramentos.

\section{ABSTRACT}

The present article hypothesizes that games are expressive and multimodal media, loaded with discourses that can materialize and elicit multiple constructions of meanings, besides being objects of entertainment. It aims to discuss games as multimodal texts, in order to propose a face of "ludic literacy" approaching the multilliteracies perspective, involving the critical reading and the possibility of materializing discourses of young students through the creation and modification of games mediated by their teachers. As a methodological course, it is based on discourse genders and multimodality studies, such as Bakhtin, Miller and Bazerman, Carvalho, Fairclough and Lemke and applies this look in the analysis of three versions of a very traditional and well-known board game, Banco Imobiliário: the version created by the designer Fabio Lopez in 2010, called "Bando Imobiliário"; the version created by Estrela for the City of Rio in 2013, "Monopoly Olympic City"; and the version elaborated by teachers of municipal public schools and exposed in Cinelândia, a month after the controversy raised by the distribution of the game bought by the City Hall in the municipal schools. The article proposes that the reflections developed inspire the creation and modification of games, at the verbal, visual or rules level, in order to incorporate polyphony from the "voices" of students and teachers and to allow that hegemonic social rules, discourses and senses, often naturalized and hidden by centripetal and authoritarian discourses, come to the surface and be problematized.

Keywords: Board games; Polyphony; Multiletramentos.

\section{RESUMO}

El presente artículo trae como hipótesis que los juegos son medios expresivos y multimodales, cargados de discursos, que pueden materializar y suscitar múltiples construcciones de sentidos, además de ser objetos de entretenimiento. Objetivo, así, discutir los juegos como textos multimodales, a fin de proponer una cara del "letramento lúdico" que se aproxime a la perspectiva de multiletramentos, involucra la lectura crítica y la posibilidad de materialización de discursos de jóvenes estudiantes por medio de la creación y modificación de juegos mediada por sus profesores. En el curso de la investigación, se basó en los estudios de géneros discursivos y multimodalidad, con base en Bakhtin, Miller y Bazerman, Carvalho, Fairclough y Lemke y aplica esa mirada en el análisis de tres versiones de un juego de tablero bastante tradicional y conocido, el Banco Inmobiliario: la versión creada por el diseñador Fabio Lopez en 2010, llamada "Bando Inmobiliario"; la versión creada por la Estrella en contrato con el Ayuntamiento de Río en 2013, "Banco Inmobiliario Ciudad Olímpica"; y la versión elaborada por profesores de escuelas públicas municipales y expuesta en Cinelândia, un mes después de la polémica planteada por la distribución del juego comprado por el Ayuntamiento en las escuelas municipales. El artículo propone que las reflexiones desarrolladas inspiren la 


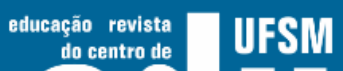

DOI: $10.5902 / 1984644430055$

creación y modificación de juegos, en el nivel verbal, visual o de las reglas, a fin de incorporar la polifonía a partir de las "voces" de alumnos y profesores y posibilitar que reglas sociales, discursos y sentidos hegemónicos, muchas veces naturalizados y ocultos por discursos centrípticos y autoritarios, salen a la luz y sean problematizados.

Palavras-chave: Juegos de Tablero; la polifonía; Multialfabetizaciones.

\section{Introdução}

O jogo está presente na vida privada das crianças e jovens e em seus momentos de lazer. Pode ser encontrado, por exemplo, nos intervalos e corredores das escolas: jogos de celular, de cartas, de tabuleiro e mesmo de representação e blefe, que não dependem de nenhum suporte material (como "Cidade Dorme", "Vítima, Assassino e Detetive"). Isso sem contar os próprios "jogos de representação", em um sentido mais amplo, que os adolescentes vivenciam diariamente, imersos em uma cultura imagética mediada por uma variedade de redes sociais.

Porém, o jogo distancia-se, muitas vezes, das aulas e dos professores, que, cobrados institucionalmente em relação aos resultados dos alunos em suas disciplinas, não o consideram como parte de seus repertórios acessíveis para a aplicação em aulas, especialmente no Ensino Médio, que se direciona para a vida profissional e para a aprovação em exames nacionais e vestibulares. Neste cenário, parece que a linguagem ou a experiência do jogo fica escondida, quase interditada do âmbito da escola, que corresponde ao saber formalizado e legitimado. Em consequência disso, quando o jogo participa deste contexto, tem, em geral, o objetivo de "consolidação" de conhecimentos, "fixação" de informações.

O presente artigo baseia-se na hipótese de que os jogos são mídias expressivas e multimodais, carregadas de discursos, que podem suscitar posturas críticas dos sujeitos e múltiplas construções de sentidos, para além de serem objetos destinados à diversão. O objetivo, assim, é discutir os jogos enquanto textos multimodais, a fim de pensar em um "letramento lúdico" (ALBUQUERQUE, 2014; ZAGAL, 2010) que se aproxime da perspectiva de multiletramentos (COPE; 


\section{- Tusm Eltua}

DOI: $10.5902 / 1984644430055$

KALANTZIS, 2000), envolva a leitura crítica e também a possibilidade de materialização de discursos de jovens estudantes por meio da criação de jogos mediada por seus professores.

Como percurso metodológico, este trabalho apresenta fundamentação nos estudos de gênero e multimodalidade, com base em Bakhtin (1997), Miller (1984) e Bazerman (1994), Carvalho (2005), Fairclough (MEURER, 2005) e Lemke (2010). A fundamentação teórica é em seguida aplicada na análise de três versões de um jogo de tabuleiro bastante tradicional e conhecido, o Banco Imobiliário: 1) a versão criada pelo designer Fabio Lopez em 2010, chamada "Bando Imobiliário"; 2) a versão criada pela Estrela em contrato com a Prefeitura do Rio em 2013, "Banco Imobiliário Cidade Olímpica"; e 3 ) a versão elaborada por professores de escolas públicas municipais e exposta na Cinelândia, um mês após a polêmica levantada pela distribuição do jogo comprado pela Prefeitura nas escolas municipais.

O presente artigo compõe uma pesquisa de doutorado sobre a criação de jogos por alunos e professores em conjunto, na Educação Básica, como estratégia de aprendizagem. Este estudo se insere no laboratório LINC-Design (Linguagem, Interação e Construção de Sentidos), que abriga pesquisas em design que estabelecem cruzamentos com os Estudos da Linguagem. O laboratório trabalha na perspectiva de que a linguagem e consequentemente os discursos mediam o acesso à realidade e a relação estabelecida com as coisas/objetos (BAKHTIN, 1997). Inclui, assim, pesquisas que busquem:

[...] compreender, refletir e propor ações sobre o discurso em uso, em situação de interação tanto na perspectiva dos atos de fala, ou das intenções decorrentes dos modos escolhidos para se dizer algo sobre o objeto de design (objeto de uso/sistema de informação/serviço), quanto na perspectiva da análise do objeto de design sobre o qual se fala e ainda quanto às construções de sentidos-ações decorrentes da inserção do objeto de design no meio social. (FARBIARZ; NOVAES, 2014, p. 122)

\section{Jogos de tabuleiro: objetos de design, sistemas de comunicação e gêneros discursivos}

Segundo Bomfim (1999), o design é uma atividade que configura objetos de uso e sistemas de informação (ou de comunicação), "extensões de um indivíduo em suas relações com outros indivíduos e com o meio ambiente" (BOMFIM, 1997, p. 


\section{EUtha}

DOI: $10.5902 / 1984644430055$

36). Os jogos, enquanto artefatos e sistemas de regras que promovem experiências (SALEN; ZIMMERMAN, 2003; SCHELL, 2015), são objetos de design, precisam ser projetados, passar por um processo de configuração projetual.

Portinari (2016) destaca que, em geral, "levar em conta o sujeito" no âmbito do design significa considerar que o ponto de partida e de chegada da atividade projetual não é o objeto ou sistema a ser projetado, mas as relações entre este e "o usuário". Por meio desse processo, o design atua na "configuração da cultura material e a sua inserção nos processos de produção de bens de consumo" (idem) e participa, assim, "da própria produção de subjetividade, na medida em que as formas de subjetividade são configuradas na cultura e nos sistemas de reprodução das relações de produção" (idem).

Assim, podemos considerar que os jogos, frutos de processos de design, funcionam como objetos de uso - individual ou coletivo - e ao mesmo tempo como sistemas de comunicação, intermediando relações entre seus usuários e construções de sentidos e identidades. Com isso, os jogos exercem diferentes funções: como antecessor da cultura, um componente fundamental desta, um mediador de conflitos, um espaço seguro para a experimentação de situações perigosas ou futuras e aprendizados diversos, como ambientes de catarse, e mesmo como pura e simples diversão (HUIZINGA, 2014; VASCONCELLOS, 2013; XAVIER; COELHO, 2007).

Aprofundando nosso olhar nos processos de configuração dos jogos enquanto objetos de design, temos, com Bomfim, que, trabalhando na configuração de objetos de uso e sistemas de comunicação, a atividade de design:

[...] incorpora parte dos valores culturais que a cerca, ou seja, a maioria dos objetos de nosso meio são antes de mais nada a materialização dos ideais e das incoerências de nossa sociedade e de suas manifestações culturais assim como, por outro lado, anúncio de novos caminhos. (BOMFIM, 1999, p. 150)

Nesse cenário complexo, o design encontra-se não necessariamente como protagonista da configuração, mas como uma das possíveis interpretações dessas tendências. Não como "regra universal de configuração, mas uma ação interpretativa, criadora, que permite diversas formas de expressão (BOMFIM, 1999, 


\section{Eutha}

p. 152).

DOI: $10.5902 / 1984644430055$

$\mathrm{Na}$ perspectiva atual dos Game Studies, área de conhecimento que busca estudar os jogos enquanto objetos culturais, compreende-se que a estratégia mais profícua de pesquisa é a coexistência de abordagens, considerando que, enquanto objeto e processo, estes são textos híbridos, e que a construção de identidades cada vez mais se dá de forma "lúdica", seja mediada pelos jogos ou por outros artefatos culturais (RAESSENS, 2012).

Pensar o design enquanto ação interpretativa e criadora, produto e produtora de sentidos sociais a partir das interações dos sujeitos com os objetos de sua produção, alinha-se com a consideração dos jogos enquanto textos híbridos, mediadores de interações e construções de subjetividades. Mais ainda, nos remete à concepção dos estudos da linguagem, especialmente de Bakhtin e de pensadores da corrente da Nova Retórica.

$\mathrm{Na}$ concepção do círculo de Bakhtin, a unidade do discurso é o enunciado, e não a frase ou a oração. Ao enfatizar a linguagem enquanto sistema de comunicação, Bakhtin destaca que esse processo se dá por meio de enunciados (orais e escritos), sempre concretos e únicos, enquanto instâncias de uso da linguagem por um sujeito locutor, conectadas a um contexto social, da atividade humana, e influenciados por esta (1997).

Os enunciados são, assim, elaborados pelos interlocutores em função de cada esfera ou contexto comunicacional, em diálogo com outros enunciados já existentes sobre o objeto do seu discurso. Ao mesmo tempo, enquanto processo interacional, a comunicação compreende interlocutores ativos: cada enunciado volta-se para a resposta do outro e para os discursos do outro sobre o objeto daquela fala. Com isso, cada enunciado pressupõe e alimenta uma compreensão responsiva ativa, ou seja, a produção de uma resposta, refutação ou confirmação, por parte dos destinatários do enunciado. As respostas, por sua vez, podem ficar interiorizadas ou manifestarem-se na forma de diferentes tipos de enunciados:

Um enunciado concreto é um elo na cadeia da comunicação verbal de uma dada esfera. As fronteiras desse enunciado determinam-se pela alternância dos sujeitos falantes. Os enunciados não são indiferentes uns aos outros nem são auto-suficientes; conhecem-se uns aos outros, refletem-se mutuamente. São precisamente esses reflexos recíprocos que thes 


\section{-

DOI: $10.5902 / 1984644430055$

determinam o caráter. $\mathrm{O}$ enunciado está repleto dos ecos e lembranças de outros enunciados, aos quais está vinculado no interior de uma esfera comum da comunicação verbal. (BAKHTIN, 1997, p. 316)

$\mathrm{Na}$ elaboração dos enunciados, Bakhtin destaca que três elementos são fundamentais: conteúdo temático, estilo e construção composicional, e aponta que os enunciados já elaborados em um dado contexto de comunicação exercem grande influência sobre a escolha e determinação desses elementos nos novos enunciados, constituindo os chamados gêneros do discurso.

Os gêneros do discurso auxiliam no processo de comunicação por serem "tipos relativamente estáveis" de enunciados, ligados a diferentes esferas de comunicação humana. Por meio do reconhecimento dos gêneros, os interlocutores podem compreender quando um enunciado foi concluído, quando é sua vez de interagir e como interagir: que conteúdos temáticos são adequados, quando e onde os estilos individuais são pertinentes e que tipos de construção composicional são adequadas e produtivas no processo de comunicação naquela determinada situação social.

O querer-dizer do locutor se realiza acima de tudo na escolha de um gênero do discurso. Essa escolha é determinada em função da especificidade de uma dada esfera da comunicação verbal, das necessidades de uma temática (do objeto do sentido), do conjunto constituído dos parceiros, etc. Depois disso, o intuito discursivo do locutor, sem que este renuncie à sua individualidade e à sua subjetividade, adapta-se e ajusta-se ao gênero escolhido, compõe-se e desenvolve-se na forma do gênero determinado. (BAKHTIN, 1997, p. 301)

Percebe-se, por esse trecho, que, apesar da força que Bakhtin atribui aos gêneros do discurso, buscando diferenciar sua concepção de linguagem do uso "livre e criativo" concebido por outras linhas da linguística, existe um espaço para a expressão da individualidade do interlocutor e para a reconfiguração dos gêneros do discurso ("tipos relativamente estáveis") em função de mudanças nas situações de comunicação, nos participantes, etc.

Os gêneros, assim, são impessoais, mas possuem uma tipificação social. Dessa forma, não são as propriedades formais ou estilísticas que definem um gênero, mas sua ligação com uma situação social de interação:

Cada gênero está assentado em um diferente cronotopos, pois inclui um horizonte espacial e temporal (qual esfera social, em que momento histórico, qual situação de interação), um horizonte temático e axiológico (qual o tema do gênero, qual a sua finalidade ideológico-discursiva) e uma concepção de autor e destinatário. (RODRIGUES, 2005, p. 165) 


\section{OF HW Eltua}

DOI: $10.5902 / 1984644430055$

Essa concepção de ligação de gêneros de discurso com situações sociais de interação é desenvolvida mais profundamente pela linha da Nova Retórica, por autores como Miller (1984) e Bazerman (1994), que consideram o gênero como ação social. Embora em Bakhtin já houvesse menção aos propósitos ou "finalidades" dos enunciados, nessa "escola" as motivações dos participantes do discurso e seus efeitos pretendidos são enfatizados, dando origem ao conceito de Miller de gênero como ação retórica tipificada: respostas a situações sociais recorrentes (1984). Consequentemente, para essa abordagem, o gênero tem o potencial de estruturar a ação social, por mediar o público e o privado, o indivíduo e a comunidade (CARVALHO, 2005). Nessa mesma linha, Paré \& Smart (apud CARVALHO, 2005) definiram que, para estudar gênero como ação social, deveria se observar: um conjunto de textos, seus processos de composição, as práticas de leitura e os papeis sociais assumidos por seus produtores e consumidores.

A dimensão constitutiva do discurso e essa relação bidirecional entre linguagem e estruturas sociais é um elemento forte na Análise Crítica do Discurso (ACD), desenvolvida por Fairclough, que trataremos a partir de Meurer (2005). Para o autor, uma ocorrência discursiva é vista ao mesmo tempo como texto, como manifestação de discursos e como prática social.

Para a ACD, os discursos moldam a maneira como os indivíduos usam seus recursos cognitivos, e os textos significam aquilo que os discursos 'permitem' que signifiquem. Notese, entretanto, que - devido à relação bidirecional entre discurso e sociedade - os indivíduos têm também a possibilidade de influenciar os discursos e de criar 'realidades' por meio do uso de textos. A ACD procura desenvolver teoria e método para mostrar que as 'realidades' representadas por meio de ações discursivas são criações sociais e não verdades absolutas. (MEURER, 2005, p. 89)

A partir dos estudos de linguagem trazidos neste artigo, temos que a linguagem, enquanto mediação da realidade, incorpora a intencionalidade dos sujeitos falantes e seu lugar, seu posicionamento social, e é carregada de ideologia, proveniente dos posicionamentos assumidos pelos sujeitos nos atos/processos de interação (FARBIARZ; NOVAES, 2014, p. 128). Porém, embora a escolha de gêneros e textos sofra pressões sociais e de instâncias de poder, Fairclough, alinhado com a perspectiva do sociólogo Anthony Giddens, considera que "cada situação de prática social é simultaneamente coercitiva ou coibidora e capacitadora" (MEURER, 2005, p. 92), fazendo ressonância ainda com a perspectiva do design 


\section{F WFH elithabal}

DOI: $10.5902 / 1984644430055$

defendida por Bomfim, apontada no início deste artigo. Vejamos agora mais especificamente como os jogos são não apenas gêneros discursivos, mas constitutivamente multimodais.

\section{Jogos de tabuleiro: gêneros discursivos multimodais e a produção de múltiplos sentidos}

O teórico lan Bogost (2010) defende a ideia da "retórica procedimental", segundo a qual valores e ideias embutidos nas regras dos jogos podem representar formas de funcionamento de processos do "mundo real", constituir argumentos e serem "passados" aos jogadores por meio da experiência de jogo. Ele considera ainda que determinados jogos que denomina "persuasivos" possuem, mais do que outros, o objetivo final de transmitir uma mensagem ou de influenciar a mudança de comportamento do jogador a partir da experiência de jogo.

Além desse termo, como evolução e desdobramento do conceito de "jogos educativos", alguns teóricos hoje em dia trabalham com os termos "jogos sérios" (serious games) ou "jogos aplicados": aqueles que, além de serem divertidos, têm um propósito na vida real, pretendem disparar mudanças de comportamento, conscientização ou algum tipo de aprendizagem nos jogadores. Esses jogos têm sido utilizados, além de educação e treinamento, como produtos que objetivam conscientizar o público sobre causas políticas e sociais (VASCONCELLOS, 2013).

Entretanto, como textos produzidos por interatores em uma sociedade mediada pela linguagem, os jogos fazem parte da cultura material como qualquer outro produto cultural e de design, como tratamos acima. Enquanto jogos analógicos (todos aqueles que não são digitais, como os jogos de tabuleiro) fazem parte da mediação de relações humanas há séculos, os videogames são hoje considerados parte de uma "cultura participatória", que ultrapassa a questão da "interatividade" do meio eletrônico, e inclui interpretação, reconfiguração e construção (RAESSENS, 2005). Assim, mesmo contendo sentidos e valores, estes não determinam a adesão aos mesmos pelos jogadores, que exercem um papel ativo, seja manipulando os elementos dos jogos como também interpretando, criticando e criando novas regras e jogos (VASCONCELLOS, 2013), o que também pode ser estendido aos jogos 


\section{Usism Eutloabुa}

DOI: $10.5902 / 1984644430055$

analógicos - as "respostas ativas" (BAKHTIN, 1997) dos interatores se materializam em múltiplas formas de produção comunicacional e subjetiva.

Partindo então dos estudos da linguagem, conforme apresentamos, todo jogo, como texto (composto de elementos verbais, visuais e procedimentais - as regras), já é constitutivamente dialógico, pois carrega em si diferentes discursos que o precedem na cultura e que o compõem, enquanto objeto de linguagem - assim como enquanto objeto de design.

Ao mesmo tempo, o jogo pode ser visto como gênero discursivo no sentido de incorporar ação social, pois media a construção de relações sociais, de identidades e de saberes sobre o mundo, e carrega sentidos sobre esses processos, materializados não só no uso da linguagem verbal, como também da visual, da retórica procedimental e de outros elementos. Os estudos de multimodalidade e letramentos multimodais, ou multiletramentos, destacam essa multiplicidade de dimensões dos enunciados como uma

[...] crescente multiplicidade e integração de modos significativos de construção de significados, onde o textual também está relacionado ao visual, sonoro, espacial, comportamental, e assim por diante. (COPE; KALANTZIS, 2000, p. 5; tradução nossa)

O "modo comportamental" aproxima-se da retórica procedimental (BOGOST, 2010), ou seja, da construção de sentidos que se dá enquanto o jogador vivencia o jogo, se comporta de acordo com (ou burlando) as regras, interage com os sentidos que as regras adicionam ao jogar.

Lemke (2010) explica que, para além dos novos discursos cuja construção é possibilitada e enfatizada pelas novas tecnologias, a multimodalidade é constitutiva de qualquer discurso, mesmo que ele seja aparentemente formado por um modo predominante, como a linguagem verbal:

[...] você nunca pode construir significado com a língua de forma isolada. É preciso que haja sempre uma realização visual ou vocal de signos linguísticos que também carrega significado não-linguístico (por ex.: tom da voz ou estilo da ortografia). Para funcionarem como signos, os signos devem ter alguma realidade material, mas toda forma material carrega, potencialmente, significados definidos por mais de um código. Toda semiótica é semiótica multimídia e todo letramento é letramento multimidiático. (LEMKE, 2010, p. 456)

Assim, retomando a ideia de gêneros enquanto ação social, Lemke destaca 


\section{Autuarão}

DOI: $10.5902 / 1984644430055$

que as interações entre os modos realizam não uma adição, mas uma "multiplicação" de sentidos, e estes nascem de - e alimentam - contextos sociais, que criam sistemas de práticas convencionais para efetivar comunicações significativas (LEMKE, 2010).

Não temos, no presente artigo, a pretensão de desenvolver uma análise de como se poderia caracterizar ou definir o gênero "jogo de tabuleiro", no sentido de buscar a "relativa estabilidade" de tais jogos, enquanto enunciados, nas cadeias de comunicação. Em vez disso, pretendemos lançar luz em alguns mecanismos discursivos presentes nesses objetos, que podem se constituir tanto em enunciados coibidores quanto capacitadores da expressão e de ações sociais, e poderiam ser considerados em práticas de letramentos multimodais com alunos na Educação Básica, como forma de desenvolver um olhar crítico e estimular a construção de seus próprios jogos/enunciados.

Segundo Meurer (2005), como vimos anteriormente, a vertente teórica da Análise Crítica do Discurso possui afinidades com a abordagem de Bakhtin, por ver a linguagem como uma prática social, que se alimenta de e ao mesmo tempo conforma práticas; e considerar que os textos são localizados historicamente numa corrente contínua de outros textos (ou "enunciados"). Porém, Fairclough vai além e busca revelar os traços e pistas de rotinas sociais complexas, das relações de poder que os perpassam e do trabalho ideológico realizado por meio da linguagem para perpetuar essas formas de poder, objetivando uma perspectiva emancipatória, de conscientização dos indivíduos a respeito desses movimentos e relações, muitas vezes ocultos ou despercebidos, permeados na linguagem.

A partir de Meurer (2005), é possível dividir a abordagem de Fairclough em uma face teórica e uma metodológica. Em sua vertente metodológica, a ACD busca não apenas descrever, mas também interpretar e explicar, analisando: texto (descrever opções gramaticais, léxico, estrutura), prática discursiva (interpretar a partir da produção, distribuição e consumo do texto, bem como aspectos interdiscursivos e intertextuais) e prática social (explicar como estas se relacionam com os textos considerados).

No presente artigo, nos inspiramos nas camadas da ACD para discutir as possibilidades de significação presentes nos jogos selecionados. Vejamos agora em 


\section{Althrapẫ}

DOI: $10.5902 / 1984644430055$

mais detalhes, a partir dessa análise, como essas concepções podem ser aplicadas na compreensão de jogos de tabuleiro em suas dimensões textual, discursiva e como prática social, com o objetivo de destacar as possibilidades de coerção e capacitação presentes nesses objetos de design, que participam de determinados tipos de ações sociais, mediando interações e experiências subjetivas.

A análise do nível do texto ("descrição") será limitada aos elementos que foram divulgados pela internet, uma vez que: o "Bando Imobiliário" é considerado um jogomanifesto e por isso não é comercializado ou distribuído; o Banco Imobiliário Cidade Olímpica teve suas cópias recolhidas após a polêmica instaurada por sua circulação; e o jogo desenvolvido pelos professores na Cinelândia possuía dimensões agigantadas e o objetivo de ser utilizado naquele momento, para fins de manifestação e de chamar atenção do público que passava. Entretanto, no nível das práticas discursivas e das práticas sociais, vamos buscar interpretar esses jogos do ponto de vista de sua produção, distribuição e consumo; e trazer conexões com as práticas sociais que os envolvem.

\section{Bando Imobiliário Carioca (2010)}

O primeiro jogo de que tratamos é o "Bando Imobiliário Carioca", criado pelo designer Fabio Lopez em 2010, na esteira do sucesso do filme Tropa de Elite e com base no relatório final da CPI das milícias, publicado em 2008. Mantendo a ideia central de "monopólio", o designer fez, de forma independente, uma paródia do jogo original, mantendo boa parte de seu modo de funcionamento, mas refletindo, em sua temática, a atuação das milícias paramilitares na cidade do Rio de Janeiro - que também se baseiam em uma lógica de monopólio. 


\section{Ẽtha \\ ISSN: $1984-6444$}

DOI: $10.5902 / 1984644430055$

Figura 1-Tela do site de divulgação do "Bando Imobiliário Carioca"

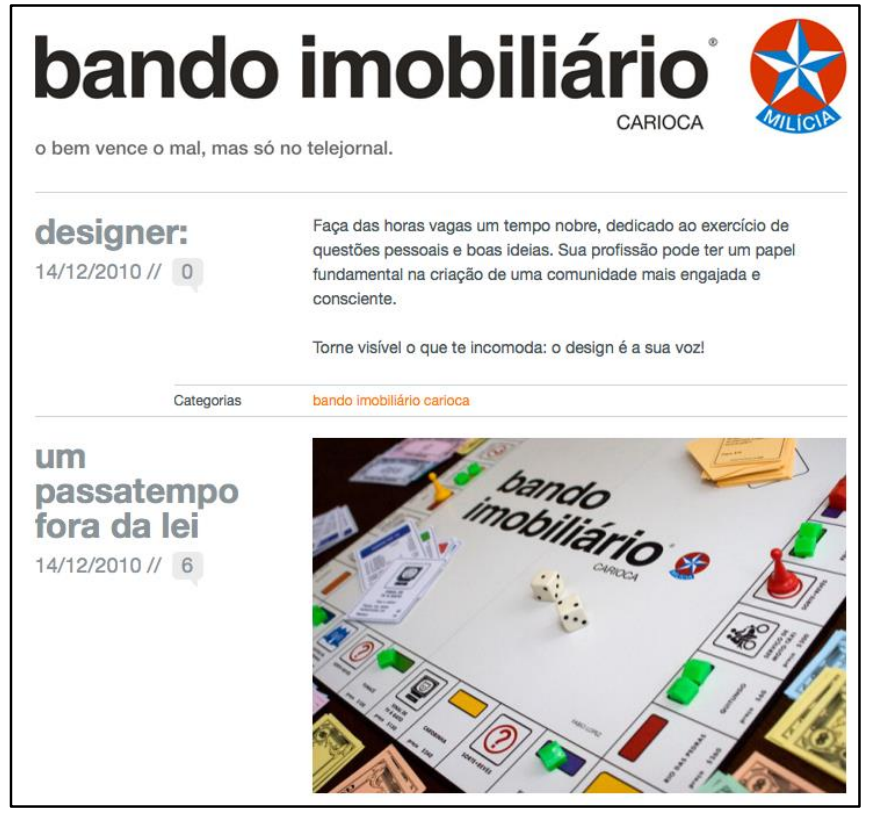

Fonte: https://bandoimobiliario.wordpress.com.

A página que contém os elementos do jogo é composta por imagens e textos dispostos em uma configuração de blog. Por meio da marcação de cronologia próprias dos blogs, pode-se perceber que os elementos foram publicizados em partes, por temas, porém em um mesmo dia (https://bandoimobiliario.wordpress.com). O autor divulga o link para o blog do jogo como um de seus principais trabalhos, em sua página profissional (http://minirio.com.br/designer.html).

O menu superior contém duas partes: "Início" e "Autor". Os títulos das partes compreendem:

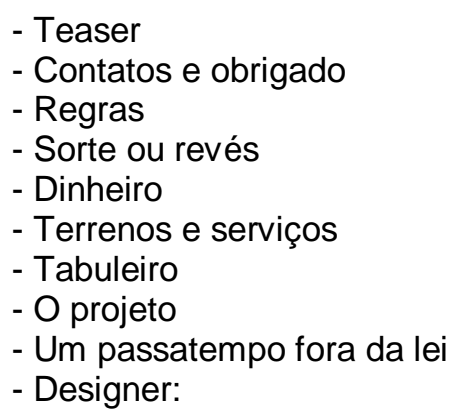

Com esses elementos, é possível ao leitor imaginar como seria jogar, especialmente por se tratar de uma versão de um jogo muito tradicional e conhecido no contexto brasileiro. Pela paródia, aproxima-se de eventuais leitores/jogadores a 


\section{Ẽtha}

DOI: $10.5902 / 1984644430055$

partir do reconhecimento do que se pode chamar de um "gênero Banco Imobiliário", tendo em vista a quantidade de variações desse mesmo jogo existentes no mercado e a presença dele na cultura brasileira, especialmente de classe média. Porém, recontextualiza esses sentidos, com um novo objetivo, deixando às claras a crítica pretendida.

O visual se mantém praticamente inalterado: as principais mudanças se dão no nível da linguagem verbal, com a mudança dos nomes e descrições: do dinheiro; dos "terrenos" e "companhias" que podem ser adquiridos e das situações presentes nas cartas de "sorte ou revés".

As cartas de propriedades tornaram-se terrenos da cidade, em geral vinculados à presença de favelas onde atuam as milícias; "pontos turísticos" como a "central telefônica de segurança máxima" Bangu 1 e o Palácio Tiradentes, sede da Assembleia Legislativa; e serviços (ou "desserviços", como ele descreve) prestados por estas, como venda de gás, segurança patrimonial, gatonet, moto-táxi, transporte alternativo e exploração de máquinas de tele-jogo.

O dinheiro, rebatizado de "Arrêgo", serve não apenas para pagar alugueis, mas também para lidar com as cartas de "sorte ou revés", que trazem um forte sentido de "realidade" ao jogo, demarcando discursos relacionados, ao vincular cada situação descrita a uma notícia de jornal: "extorsões, dívidas, mandatos de prisão, advogados, gasolina adulterada, carros de luxo e um pouquinho de violência" carregam junto as fontes de onde foram retiradas.

Assim, o jogo se apresenta claramente como gênero secundário, na perspectiva de Bakhtin (gêneros complexos: que incorporam e transmutam gêneros simples em sua constituição), por incorporar gêneros primários (simples: diálogo cotidiano, carta, entre outros). Ao serem incorporados dentro dos gêneros complexos, os gêneros simples ganham novos sentidos e naturezas, pois deixam de relacionar-se à situação real e concreta que seria de sua origem e passam a compor a realidade concreta do gênero secundário: por exemplo, um romance que incorpora diálogos e cartas (ou um jogo que, entre seus componentes, articula notícias de jornal, que por sua vez incorporam diálogos, ressignificando-os). 


\section{Fism Eutlbabato}

DOI: $10.5902 / 1984644430055$

Figura 2- Tabuleiro do "Bando Imobiliário Carioca".

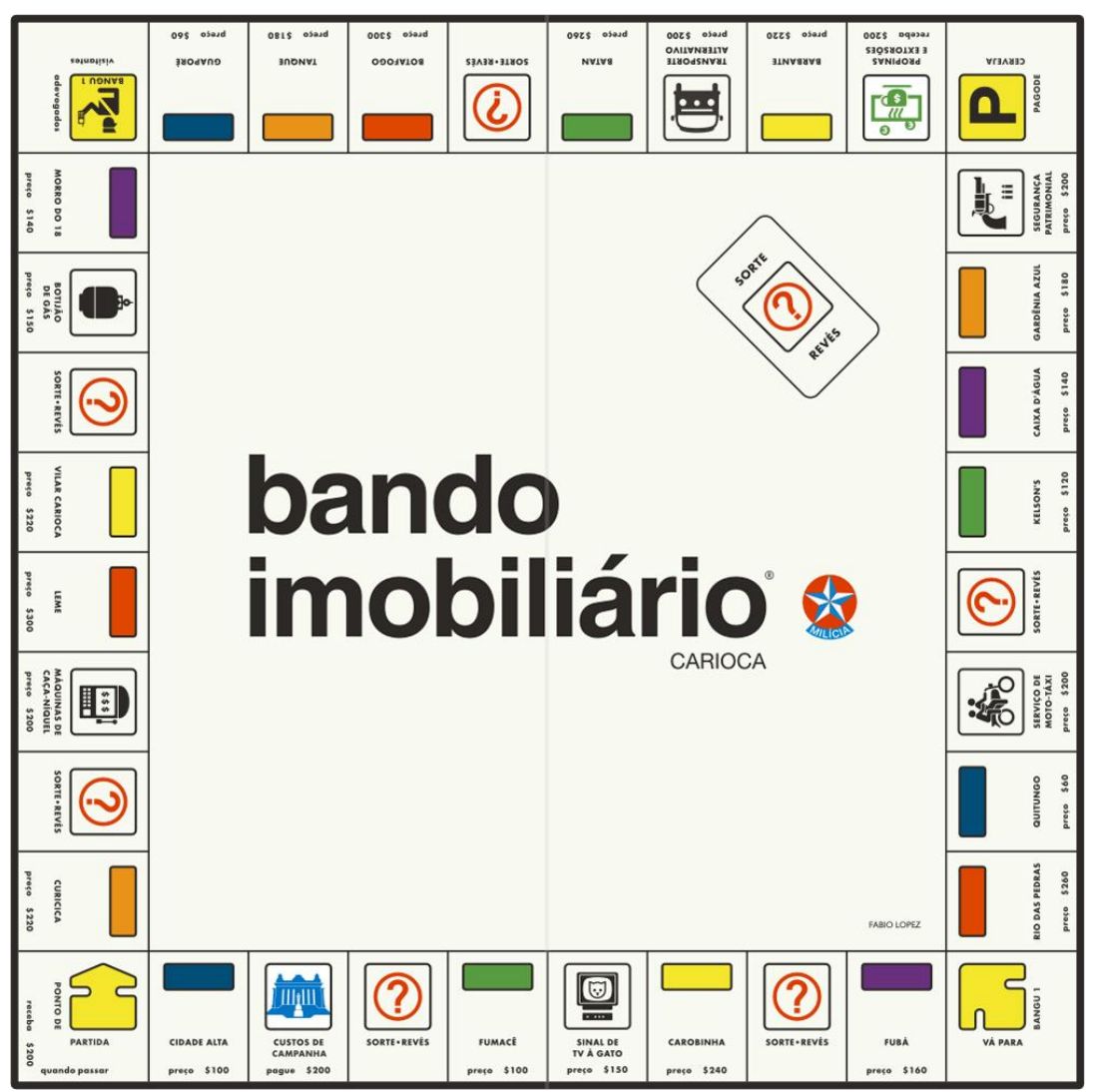

Fonte: https://bandoimobiliario.wordpress.com.

A imagem do tabuleiro revela mais alguns elementos que indicam a natureza sarcástica e autoral do jogo: ele contém, além dos espaços modificados do próprio tabuleiro, o nome do autor; o nome do jogo modificado, na mesma tipografia do jogo original; e a marca que remete à da empresa produtora do jogo original: ao colocar mais uma ponta na estrela, e associá-la ao nome "milícia", ele evita uma acusação de uso indevido da marca, e ainda pode gerar uma associação com um distintivo policial.

Porém, ao analisar as práticas discursivas correspondentes (MEURER, 2005), podemos perceber que a crítica não está só "dentro" do jogo. Em vários momentos, Lopez explicita suas intenções e explica posicionamentos tomados no projeto. No item “Designer:", se assume enquanto autor e propõe que outros designers assumam esse lugar de autoria e crítica:

Faça das horas vagas um tempo nobre, dedicado ao exercício de questões pessoais e boas ideias. Sua profissão pode ter um papel fundamental na 


\section{T usm Ellloahá}

DOI: $10.5902 / 1984644430055$

criação de uma comunidade mais engajada e consciente.

Torne visível o que te incomoda: o design é a sua voz! (LOPEZ, 2010)

No item que descreveria as "regras", o designer traz mais um comentário:

O objetivo moral do jogo se manteve inalterado: ensinar a crianças e adultos as relações nocivas do capitalismo, baseadas na exploração de seus amigos até que a falência os obrigue a buscar um outro divertimento.

Para o jogo se tornar ainda mais emocionante você pode apimentar a partida com todo tipo de maracutaia: desvio de verbas, agiotagem, superfaturamento e caixa 2 - fique à vontade. A única regra intocável é: se não pagar, vai apanhar! (LOPEZ, 2010)

As regras (o modo "comportamental" proposto pelo designer), portanto, não diferem muito das do jogo original. Porém, ao incorporar tantas mudanças ao texto das cartas e do tabuleiro, o jogo pode gerar significados muito diferentes daqueles do jogo original. Essas mudanças estão associadas ainda aos vários comentários do autor, que poderiam não estar disponíveis para eventuais jogadores, caso fosse um jogo comercial, mas o fato de ele não comercializar o jogo, somente divulgar como um "manifesto", faz com que esses comentários tenham uma força muito grande na construção dos sentidos presentes no jogo, participando como uma forma de "legenda", um discurso que está "fora" do jogo mas ao mesmo tempo o acompanha e carrega de sentidos.

Com tudo isso, a ação retórica tipificada (MILLER, 1984) em que se insere geralmente um jogo de tabuleiro - um momento de descontração e interação, muitas vezes infantil - verte-se em um movimento de crítica social e política, que não pode se realizar plenamente enquanto jogo, tendo em vista que o designer se posicionou contrário à sua mercantilização, publicizando-o apenas como um "jogo-manifesto":

Prefiro que este projeto seja apresentado como uma reflexão, não como produto. $\mathrm{O}$ intuito é gerar uma discussão e não entretenimento. Também acho que seria de extremo mau gosto comercializar um produto que retrata de maneira tão cínica uma realidade dura para muitas pessoas. (In: COHEN, 2013)

Esse posicionamento retira o jogo do contexto de outros jogos de tabuleiro, que seria o da apropriação, em geral em ambientes domésticos, por grupos de crianças, adolescentes ou adultos, com objetivos de entretenimento, mas reforça seu potencial como disparador de discussão e reflexão. O "mau gosto" e o "cinismo" apontados por Lopez e essa separação de qual deveria ser o "lugar" de um jogo como esse 


\section{WEM entinabal}

DOI: $10.5902 / 1984644430055$

refletem a ideia de "grotesco" e "vulgar" (BRAIT, 2007). Lopez deu forma e existência a um discurso cuja linguagem encontra-se com o conceito bakhtiniano de "extraterritorialidade", com a definição de um território estabelecido socialmente, entrelaçando ético e estético:

[...] aquilo que é de mau gosto no sentido ético ou até mesmo estético é, em geral, um discurso que se opõe a discursos oficiais, às diferentes normas reconhecidas e praticadas num dado momento. É aquilo que rompe a superfície da norma e põe à mostra seus latentes subterrâneos. (BRAIT, 2007, p. 76)

Com o slogan "O bem vence o mal, mas só no telejornal", o jogo se apresenta como "um passatempo fora da lei", o que pode ser interpretado como um jogo que trata de práticas ilegais, mas também como um jogo que se coloca fora das leis, fora das "normas" do que é "aceitável" para um "jogo de salão".

O "Bando Imobiliário Carioca" é um enunciado que funciona como uma resposta do designer à estrutura violenta e corrupta estabelecida na cidade, às notícias circulantes, à midiatização da atuação - e da corrupção - policial e miliciana. Ele incorpora explicitamente vozes dos noticiários, da CPI e provavelmente de outros discursos encontrados enquanto morador da cidade, mas esse cruzamento foi viabilizado por meio de sua "voz" como designer, exercendo seu papel de criação de uma "resposta ativa" aos discursos circulantes da pacificação e da especulação imobiliária.

\section{Banco Imobiliário Cidade Olímpica}

Contratado pela Prefeitura em 2013, o jogo "Banco Imobiliário Cidade Olímpica" apresenta elementos muito diferentes da versão de Fabio Lopez. Em vez de estimular uma visão crítica e o desenvolvimento dos saberes necessários à resolução de problemas do ambiente urbano brasileiro, como desigualdades no acesso à infraestrutura, aos serviços públicos e à moradia digna (DEL'ESPOSTI; CRUZ, 2015), os jogadores encontram a seu dispor - para compra e "investimento" - equipamentos públicos, como Clínicas da Família, obras da Prefeitura, como Porto Maravilha (projeto para a zona portuária), Parque Madureira e Centro de Operações Rio (que monitora tráfego e serviços públicos) (BRISOLLA, 2013). As cartas de "sorte ou revés" exibem mensagens como: "Seu imóvel foi valorizado com a pacificação da 


\section{Eutlpapão}

DOI: $10.5902 / 1984644430055$

comunidade vizinha. Receba $\mathrm{R} \$ 75$ mil” (idem). Com a inauguração do corredor de ônibus BRT, o jogador fica sabendo que economizará $\mathrm{R} \$ 10$ mil em passagens.

Figura 3- Tabuleiro do jogo "Banco Imobiliário Cidade Olímpica".

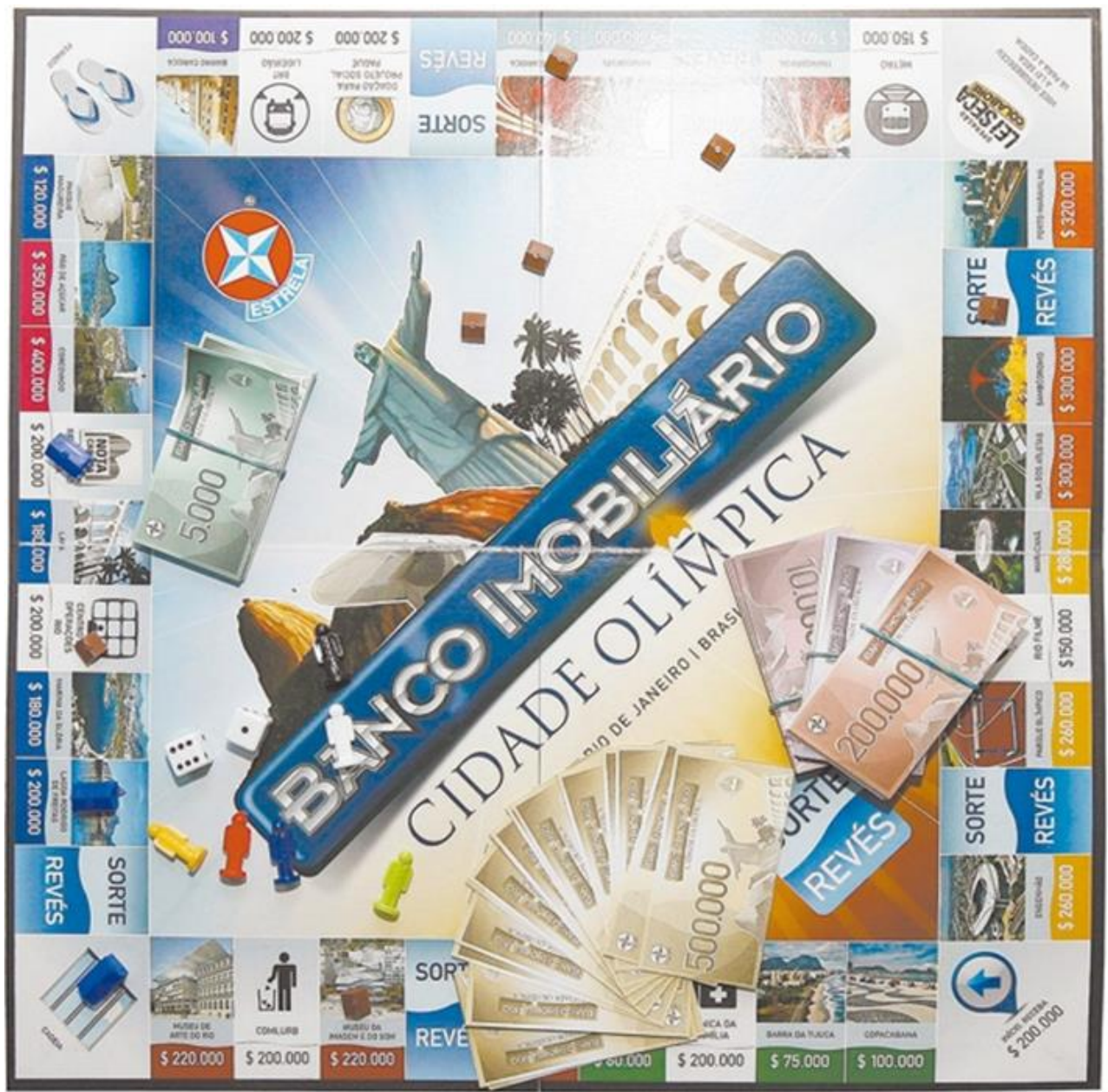

Fonte: (ROLNIK, 2013).

Ou seja, o jogo coloca equipamentos públicos como produtos comercializáveis e que podem dar retorno financeiro, além de valorizar a especulação imobiliária e exaltar as obras da Prefeitura. Assim, funciona como uma "resposta" (no sentido bakhtiniano) à necessidade de "fixar o mito" da Cidade Olímpica e dos "feitos" da administração municipal.

Conquanto, para Bakhtin, a linguagem e o discurso sejam em si dialógicos, em termos de sua constituição e relação com os discursos circulantes, pode-se caracterizar a monofonia ou a polifonia, em função das estratégias discursivas empregadas nos textos. Barros (2007) relaciona esses conceitos com as ideias de discursos "autoritários" ou "poéticos": 


\section{Tusm Ellubahao}

DOI: $10.5902 / 1984644430055$

Nos discursos autoritários, abafam-se as vozes, escondem-se os diálogos e o discurso se faz discurso da verdade única, absoluta e incontestável. A única forma de contestar tais discursos é recuperar externamente a polêmica escondida, os confrontos sociais, ou seja, contrapor ao discurso autoritário um outro discurso, responder a ele, com ele dialogar, polemizar. O discurso poético, por sua vez, é aquele que expõe, que mostra ou que deixa escutar o dialogismo que o constitui, a heterologia discursiva, as vozes contraditórias dos conflitos sociais." (BARROS, 2007, p. 34)

O jogo produzido por demanda da Prefeitura, assim, ao mesmo tempo em que reforça a ideologia de mercantilização da cidade (DEL'ESPOSTI; CRUZ, 2015), age como "discurso centrípeto", uma voz que reflete a voz das autoridades e da lógica de mercado presentes no espaço público, e abafa, no jogo, quaisquer vozes discordantes ${ }^{1}$.

Após o lançamento do jogo, a polêmica nos jornais e nos sites de redes sociais esteve centrada especialmente na destinação de recursos da Secretaria Municipal de Educação para a compra de 20 mil unidades do jogo e sua posterior distribuição nas Escolas Municipais. Em nota, a Secretaria de Educação justificava a distribuição com o argumento de que os professores poderiam "utilizar os jogos em disciplinas como geografia, história e matemática e ainda falar de temas como a preservação dos espaços culturais da cidade", e de que o jogo mostraria, ainda, "uma visão mais contemporânea da cidade" (Nota da Prefeitura, In: MENDONÇA, 2013).

Podemos dizer que os produtores desse jogo não consideraram nem os gêneros discursivos como ação social, nem a possibilidade de "resposta ativa" do público. Pensando no gênero "jogo educativo", "jogo persuasivo", ou "jogo sério", talvez o estilo e a construção composicional estivessem adequadas: uma adaptação muito básica de um jogo já muito conhecido, que teria potencial para uma adesão facilitada de professores e alunos. Porém, em termos de conteúdo e de ação social em si, percebem-se inúmeras inadequações. A "resposta ativa" do público, especialmente de professores, fez notar esses problemas em sua avaliação e seu posicionamento público: a crítica incluiu o conteúdo, considerado laudatório e superficial, a Prefeitura que o encomendou e o conjunto de suas demais ações em

\footnotetext{
${ }^{1}$ Após muita discussão e o início de uma investigação do Ministério Público, as unidades que seriam distribuídas nas escolas foram recolhidas e o jogo não aparece hoje no site da fabricante. Porém, uma edição do jogo chamada "Banco Imobiliário Rio de Janeiro", com uma identidade visual semelhante, pode ser encontrada à venda em lojas de brinquedos.
} 


\section{Ailloapẫ}

DOI: $10.5902 / 1984644430055$

relação aos professores e escolas, e o próprio "formato" da proposta, por se gastar dinheiro público com o que pareceu mais uma "propaganda" da Prefeitura imposta aos professores, sem uma discussão fundamentada de fato sobre a cidade, que pudesse contribuir para a formação dos alunos.

\section{Banco Imobiliário Cidade Olímpica - versão dos professores}

Aproximadamente um mês após a polêmica dos jogos que seriam distribuídos nas salas de aulas, representantes do Sindicato dos Profissionais da Educação (Sepe-RJ) apresentaram na Cinelândia uma nova versão dele. Sobre o tabuleiro, impresso em uma lona gigante, colocada no chão, era possível ver, nas cartas de "Sorte ou Revés", atitudes da Secretaria Municipal de Educação, como: a diminuição da autonomia pedagógica, a retirada da regra de lotação das escolas, e mesmo críticas ao jogo comprado pela Prefeitura: "A edição Cidade Olímpica [...] induz alunos a aceitar [...] do prefeito como maravilhas da cidade" (a imagem não permite visualizar o conteúdo completo da carta). As consequências variavam desde multas até a demissão da Secretária Municipal de Educação e, no último caso, a carta dizia que o prefeito responderia judicialmente por "propaganda eleitoral indevida" (AFFONSO, 2013).

Segundo a notícia, o jogo foi palco de uma peça teatral. Não sabemos se ele foi "jogado" enquanto tal. Talvez, por tratar-se de denúncia de caráter sócio-político, o jogo produzido pelos professores denunciando as condições de trabalho não possa chegar a ser considerado um "discurso carnavalizado", que deveria incorporar a ambivalência, mas certamente atua como "força centrífuga", descentrando a voz da autoridade, desconstruindo as verdades oficiais contidas nos discursos do jogo "Cidade Olímpica" e colocando no centro - do texto e da praça - as vozes dos sujeitos-professores. 


\section{Eutlathẫ}

DOI: $10.5902 / 1984644430055$

Figura 4- Professores exibindo o jogo "Banco Imobiliário Cidade Olímpica" modificado, em intervenção na Cinelândia.

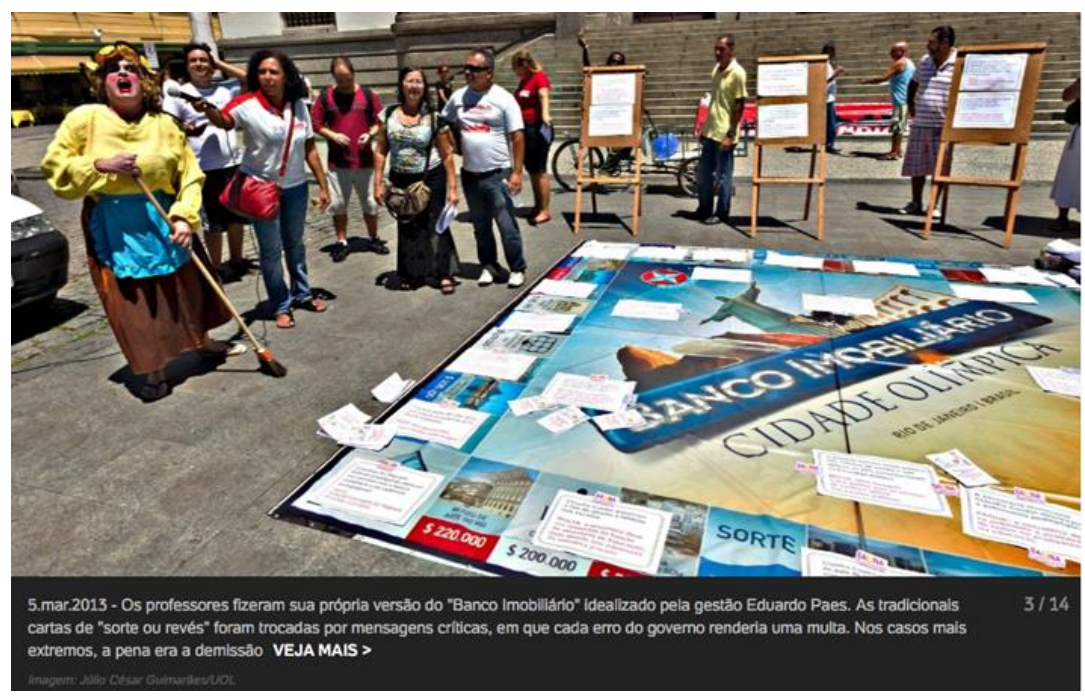

Fonte: (AFFONSO, 2013).

Comparando o jogo da Prefeitura com o jogo dos professores, fica claro como as realidades apresentadas por meios discursivos são criações sociais, como na perspectiva de Fairclough (Meurer, 2005). Ao mesmo tempo, revela-se que, além de o discurso ser constitutivo, certas "realidades" são naturalizadas por meio dele, ou seja, passam a ser percebidas como "naturais", legítimas e imutáveis, e precisam ser analisadas para que sua característica discursiva seja revelada e se permita, assim, sua desconstrução (idem). Essas duas concepções são fundamentais para a ideia de um letramento crítico.

\section{Um letramento crítico multimodal com os jogos de tabuleiro}

Para lidar com gêneros multimodais, o grupo de Nova Londres propôs uma pedagogia de multiletramentos, que focasse em modos de representação mais amplos que a linguagem em si, considerando a cultura e os contextos sociais e incluindo a linguagem e outros modos de significação como "[...] recursos representacionais dinâmicos, constantemente sendo refeitos por seus usuários enquanto trabalham para atingir seus vários propósitos culturais" (COPE; KALANTZIS, 2000, p. 5; tradução nossa). Nesse desenvolvimento, os autores buscaram então conceituar o que seria o foco da pedagogia de multiletramentos, e, 


\section{W WEM \\ ISSN: 1984-6444 \\ Ellloahá}

DOI: $10.5902 / 1984644430055$

curiosamente, a palavra "design" foi escolhida como o foco: design de sentidos por meio de múltiplos modos de significação, que alimentam o design de "futuros sociais".

O conceito chave que desenvolvemos para fazer isso é o de design, no qual somos tanto herdeiros de padrões e convenções de sentido quanto ao mesmo tempo designers ativos de sentido. E, como designers de sentido, somos designers de futuros sociais - futuros de ambientes de trabalho, futuros públicos, e futuros de comunidades. (COPE; KALANTZIS, 2000, p. 7 ; tradução nossa)

Optamos por não traduzir a palavra "design". Poderíamos ter traduzido, em momentos diferentes da citação, como "construção", porém, em inglês, a palavra denomina, geralmente, plano, projeto ou desenho, e também o resultado desse projeto. O sentido de planejar, projetar está sempre presente, assim como o de considerar um público como destinatário do que se projeta, projetar algo para alguém. É evidente que os autores se referem a enunciados que são mais amplos do que o que se costumaria considerar como "produtos de design", mas é inegável que esses sentidos se coadunam com a conceituação de design proposta por Bomfim e apresentada no início deste artigo: a configuração de objetos de uso e sistemas de comunicação, que intermediam relações sociais e a construção de identidades, carregando sentidos sobre a realidade, participando na confirmação ou questionamento de sentidos já existentes.

Nos casos analisados, três produtos de design com estilos e construções composicionais análogas - partindo do modelo do jogo "Banco Imobiliário" mostram três diferentes "sujeitos" realizando processos de design de presentes e futuros sociais. Um "designer-autor" (que abertamente se propõe a produzir uma crítica, que não se pretende jogo enquanto tal, objeto de interação); um "designer oculto" (que não é nomeado, mas produz um jogo para fixar sentidos de uma voz de autoridade); e o que poderíamos chamar de um "designer coletivo", que subverte os sentidos centrípetos colocados pela autoridade e coloca o jogo em dimensões gigantes, que os corpos vivenciam de maneira diferente.

Em função dos exemplos discutidos, podemos considerar que, ao jogar, os sujeitos produzem ("design"), de diferentes formas, diferentes aspectos de suas 


\section{Eulfoapão}

DOI: $10.5902 / 1984644430055$

subjetividades: interpretam e elaboram sentidos, reconfiguram e manipulam os elementos oferecidos pelos criadores dos jogos. Porém, essa participação se faz de maneira ainda mais radical ao se incorporar a posição de autoria, modificando jogos já existentes ou criando jogos inéditos, quando pode-se abrir ainda mais espaço para a expressão pessoal, dependendo, é claro, da situação social em que se está, de suas bagagens culturais, e das restrições colocadas a essa produção, ou seja, do lugar que se permite a eles ocupar.

\section{Considerações finais}

Como afirma Fiorin (2008), na concepção de Bakhtin cada enunciado é heterogêneo, contendo sempre no mínimo duas vozes: a que revela a sua posição e aquela em oposição à qual ela se constrói. Com isso, exibe seu direito e seu avesso, enquanto afirma, expõe sua negação. O "Bando Imobiliário", por meio da ironia e da incorporação de temas, situações e falas do mundo da milícia do Rio de Janeiro, coloca em questão a necessidade e a dificuldade de combater essas estruturas e se contrapõe a alguns discursos veiculados nas mídias jornalísticas em relação à situação da segurança pública. O jogo da "Cidade Olímpica" expõe sua voz predominante e mercadológica, porém carrega consigo a crítica, externalizada nos diversos textos produzidos contra sua distribuição nas escolas, por sujeitos que leram os sentidos ali presentes e produziram suas respostas. Os professores presentes na manifestação, ao criar e expor sua versão do jogo produzido pela Prefeitura, apresentaram uma crítica materializada no mesmo "gênero" de discurso, fazendo o trabalho centrífugo de desmontar as vozes dominantes e inserir as suas próprias vozes no enunciado da vez.

Eagleton (2007) defende uma visão da estética como âmbito político, que, ao mesmo tempo em que coloca o corpo e os sentidos em evidência, funciona estabelecendo instâncias de opressão; conquanto se apresenta como protótipo da subjetividade no princípio da sociedade capitalista, apresenta também dimensões potencialmente positivas e emancipatórias, "a visão radical das potências humanas como fins em si mesmas, o que a torna o inimigo implacável de todo pensamento dominador ou instrumental" (2007, p. 13). 


\section{ON WFH \\ ISSN: 1984-6444 \\ Ellloahao}

DOI: $10.5902 / 1984644430055$

Apresentamos neste artigo alguns exemplos de construção - ou modificação de jogos, que podem gerar polifonia, abrigar provocações estéticas, atuar politicamente, até mesmo em um viés "ativista", isso tudo trabalhando fundamentalmente na modificação do âmbito verbal e visual de um jogo de tabuleiro. Fica para imaginarmos, então, o que pode surgir ao provocar esse tipo de criação no nível procedimental, das regras. Estas podem funcionar como mais um modo para veicular enunciados e carregar essas vozes para ter contato com outras vozes de outros sujeitos. As regras sociais, os discursos e sentidos hegemônicos, às vezes naturalizados e ocultos por discursos centrípetos e autoritários, podem vir à tona, ser questionados, problematizados, "contaminados" de outras possibilidades.

A dúvida, em contextos educacionais, muitas vezes passa ainda por representar um "mundo ideal" (o que "gostaríamos que os alunos aprendessem") ou um mundo mais próximo do real, com suas vicissitudes, incoerências, absurdos, situações inverossímeis (como afirma Lopez a respeito do Bando Imobiliário). No último caso, é interessante notar o sentido de paródia, de ironia, que põe os desafios em pauta e os absurdos à prova, provocando o questionamento a respeito de como agir para modificá-los.

Alunos e professores podem, assim, participar de um movimento de criação coletiva que provoque a expor e negociar suas vozes e sentidos, criar seus próprios "mitos" e brincar com alguns já existentes, questionando que valores querem reproduzir, quais recombinar, refutar, questionar, que sentidos expressar, e como fazê-lo. Dessa forma, a narratividade dos jogos, que compõe a experiência do jogador, fica explícita também ao se exercer a atividade de criação de jogos.

As interfaces do design com a educação, mediadas pelo olhar da linguagem, como quaisquer outras formas de atuação do design, podem servir para reforçar fechamentos ou aberturas de sentidos e como espaço para produção de subjetividades. As dificuldades tanto do design quanto da educação passam pela tensão entre serem "científicos" e/ou "humanos" (JAPIASSU, 1982). Porém, a riqueza dessas duas áreas também deve ser essa: trabalhar com "objetos que 


\section{F WFH \\ ISSN: 1984-6444

DOI: $10.5902 / 1984644430055$

falam", sujeitos, complexos, simultaneamente individuais e sociais, vinculados a diferentes contextos.

Enxergar e trabalhar os jogos como objetos de design e como enunciados, partes de gêneros multimodais, meios de expressão e intervenção na realidade, aponta para uma educação que incorpore mais vozes, junto a um design que "anuncie caminhos", abrindo espaços de expressão dos sujeitos envolvidos e de produção de suas próprias subjetividades.

Barthes (1978) coloca, na língua, o peso da sujeição - "falar é sujeitar", o signo é gregário, não permite comunicar nada "fora" dele -, porém, ao mesmo tempo, defende uma literatura - as pegadas de uma prática de escrever - que seja "escritura", incorpore "sabor" ao "saber". A partir do caminho percorrido neste artigo, esperamos provocar respostas discursivas e incentivar práticas que, com Bakhtin, permitam criar enunciados mais "poéticos", mais polifônicos, menos autoritários, mais carnavalizados. Com Bomfim, anunciar caminhos. E, voltando a Barthes: criar jogos enciclopédicos, com jeito dessa "literatura" que incorpora o "sutil" da vida, mobiliza saberes diversos e misturados, "não diz que sabe alguma coisa, mas que sabe de alguma coisa; ou melhor; que ela sabe algo das coisas - que sabe muito sobre os homens" (1978, p. 17).

\section{Referências}

AFFONSO, J. No Rio, professores usam "Banco Imobiliário" de Paes para protestar. Disponível em: <http://educacao.uol.com.br/noticias/2013/03/05/no-rioprofessores-usam-banco-imobiliario-de-paes-para-protestar-e-pedir-aumento.htm>. Acesso em: 16 dez. 2016.

ALBUQUERQUE, R. M. DE. LETRAMENTO ELETROLÚDICO COMO CONSCIENTIZAÇÃO: bases teóricas para educar o jogar. Currículo sem Fronteiras, v. 14, n. 2, p. 57-74, 2014.

BAKHTIN, M. M. Estética da criação verbal. Traducao Maria Ermantina Galvão G. Pereira. 2. ed. São Paulo: Martins Fontes, 1997.

BARROS, D. L. P. DE. Contribuições de Bakhtin às teorias do texto e do discurso. In: FARACO, C. A. et al. (Eds.). . Dialogos com Bakhtin. Série Pesquisa / UFPR, Universidade Federal do Paraná. 4. ed ed. Curitiba: Ed. da UFPR, 2007. 


\section{F WsM \\ ISSN: 1984-6444

DOI: $10.5902 / 1984644430055$

BARTHES, R. Aula. Traducao Leyla Perrone-Moisés. São Paulo: Cultrix, 1978.

BAZERMAN, C. Systems of Genres and the Enactment of Social Intentions. In: FREEDMAN, A.; MEDWAY, P. (Eds.). . Genre and the New Rhetoric. London, UK: Taylor \& Francis, 1994. p. 79-101.

BOGOST, I. Persuasive Games: The Expressive Power of Videogames. Cambridge, MA: MIT Press, 2010.

BOMFIM, G. A. Fundamentos de uma Teoria Transdisciplinar do Design: Morfologia dos Objetos de Uso e Sistemas de Comunicação. Estudos em Design, v. 5, n. 2, p. 27-41, 1997.

BOMFIM, G. A. Coordenadas cronológicas e cosmológicas como espaço das transformações formais. In: COUTO, R. M. DE S.; DE OLIVEIRA, A. J. (Eds.). . Formas do design: por uma metodologia interdisciplinar. Rio de Janeiro: $2 A B$, 1999. p. 137-155.

BRAIT, B. A natureza dialógica da linguagem: formas e graus de representação dessa dimensão constitutiva. In: FARACO, C. A. et al. (Eds.). . Dialogos com Bakhtin. Série Pesquisa / UFPR, Universidade Federal do Paraná. 4. ed ed. Curitiba: Ed. da UFPR, 2007.

BRISOLLA, F. "Banco Imobiliário" exalta as realizações do prefeito do Rio 22/02/2013 - Poder - Folha de S.Paulo. Disponível em: $<$ http://www1.folha.uol.com.br/poder/2013/02/1234825-banco-imobiliario-exalta-asrealizacoes-do-prefeito-do-rio.shtml>. Acesso em: 16 dez. 2016.

CARVALHO, G. DE. Gênero como ação social em Miller e Bazerman: o conceito, uma sugestão metodológica e um exemplo de aplicação. In: MEURER, J. L.; BONINI, A.; MOTTA-ROTH, D. (Eds.). . Gêneros: Teorias, métodos, debates. São Paulo: Parábola, 2005. p. 130-149.

COHEN, M. Paródia de jogo clássico, "Bando Imobiliário" critica "expansão das milícias no Rio". Disponível em: <http://oglobo.globo.com/cultura/megazine/parodia-de-jogo-classico-bando-

imobiliario-critica-expansao-das-milicias-no-rio-7394522>. Acesso em: 16 dez. 2016.

COPE, B.; KALANTZIS, M. (EDS.). Multiliteracies: literacy learning and the design of social futures. London; New York: Routledge, 2000.

DEL'ESPOSTI, B. DOS S.; CRUZ, J. L. V. DA. O Rio no tabuleiro: a ideologia da mercantilização da cidade virou jogo. . In: XIV SEMINÁRIO DE INTEGRAÇÃ̃O DO PROGRAMA DE MESTRADO EM PLANEJAMENTO REGIONAL E GESTÃO DA CIDADE - "PENSANDO A REGIÃO - TENSÕES E POSSIBILIDADES". Rio de Janeiro: Universidade Cândido Mendes, 2015Disponível em: $<$ http://seminariodeintegracao.ucamcampos.br/images/arquivos/2015/O_RIO_NO_TABULEIRO.pdf $>$. Acesso em: 16 


\section{Wusm \\ ISSN: 1984-6444 \\ elithabal}

dez. 2016

DOI: $10.5902 / 1984644430055$

EAGLETON, T. A ideologia da estética. Traducao Mauro Sá Rego Costa. Rio de Janeiro: Jorge Zahar Editor, 2007.

FARBIARZ, J. L.; NOVAES, L. Apostando no "e" ou estabelecendo pontes entre Design e Estudos da Linguagem. In: COUTO, R. M. DE S. et al. (Eds.). . Formas do Design: por uma metodologia interdisciplinar. 2. ed. Rio de Janeiro: Rio Books, 2014. p. $121-146$.

FIORIN, J. L. Introdução ao pensamento de Bakhtin. 1. ed. São Paulo: Ática, 2008.

HUIZINGA, J. Homo ludens: o jogo como elemento da cultura. 8. ed. São Paulo: Editora da Universidade de S. Paulo, Editora Perspectiva, 2014.

JAPIASSU, H. Nascimento e morte das ciências humanas. Rio de Janeiro: Francisco Alves, 1982.

LEMKE, J. L. Letramento metamidiático: transformando significados e mídias. Trabalhos em Linguística Aplicada, v. 49, n. 2, p. 455-479, dez. 2010.

LOPEZ, F. bando imobiliário carioca. Disponível em: $<$ https://bandoimobiliario.wordpress.com/>. Acesso em: 16 dez. 2016.

MENDONÇA, A. V. Banco Imobiliário com obras da Prefeitura do Rio gera polêmica. Disponível em: <http://g1.globo.com/rio-dejaneiro/noticia/2013/02/banco-imobiliario-com-obras-da-prefeitura-do-rio-gerapolemica.html>. Acesso em: 16 dez. 2016.

MEURER, J. L. Gêneros textuais na análise crítica de Fairclough. In: MEURER, J. L.; MOTTA-ROTH, D. (Eds.). . Gêneros: Teorias, métodos, debates. São Paulo: Parábola, 2005. p. 81-106.

MILLER, C. Genre as social action. In: FRIEDMAN, A.; MEDWAY (Eds.). . Genre and the New Rhetoric. London, UK: Taylor \& Francis, 1984. p. 23-42.

PORTINARI, D. Notas de aula. Aulas de contextualização. . In: DISCIPLINA: QUESTÕES DA SUBJETIVIDADE NO DESIGN. Rio de Janeiro: Pontifícia Universidade Católica do Rio de Janeiro, 2016

RAESSENS, J. F. F. Computer games as participatory media culture. In: RAESSENS, J. F. F.; GOLDSTEIN, J. (Eds.). . Handbook of Computer Game Studies. Cambridge, MA: The MIT Press, 2005. p. 373-389.

RAESSENS, J. F. F. Homo Ludens 2.0: the ludic turn in media theory. Traducao Aleide Giberthe Fokkema. Utrecht: Universiteit Utrecht, Faculteit Geesteswetenschappen, 2012. 


\section{Authabูão}

DOI: $10.5902 / 1984644430055$

RODRIGUES, R. H. Os gêneros na perspectiva dialógica da linguagem: a abordagem de Bakhtin. In: MEURER, J. L.; BONINI, A.; MOTTA-ROTH, D. (Eds.). . Gêneros: Teorias, métodos, debates. São Paulo: Parábola, 2005. p. 152-183.

ROLNIK, R. Banco imobiliário Cidade Olímpica: seria cômico se não fosse trágico. blog da Raquel Rolnik, 27 fev. 2013. Disponível em: $<$ https://raquelrolnik.wordpress.com/2013/02/27/banco-imobiliario-cidade-olimpicaseria-comico-se-nao-fosse-tragico/>. Acesso em: 21 nov. 2017

SALEN, K. T.; ZIMMERMAN, E. Rules of Play. Kindle ed. Cambridge, MA: The MIT Press, 2003.

SCHELL, J. The art of game design: a book of lenses. Second edition ed. Boca Raton: CRC Press, 2015.

VASCONCELLOS, M. S. DE. Comunicação e Saúde em Jogo: Os video games como estratégia de promoção da saúde. Rio de Janeiro: Instituto de Comunicação e Informação Científica e Tecnológica em Saúde, Pós-Graduação em Informação e Comunicação em Saúde, 2013.

XAVIER, G. DE A.; COELHO, L. A. Imagética eletrolúdica: a visualidade dialógica no multiverso dos jogos eletrônicos. Dissertação (Mestrado)-Rio de Janeiro: Departamento de Artes e Design, Pontifícia Universidade Católica do Rio de Janeiro, 2007.

ZAGAL, J. P. Ludoliteracy: defining, understanding, and supporting games education. Pittsburgh, PA: ETC Press, 2010.

\section{Correspondência}

Cynthia Macedo Dias - Escola Politécnica de Saúde Joaquim Venâncio (EPSJV/Fiocruz), Av. Brasil, 4365 - Manguinhos. CEP: 21040-900. Rio de Janeiro, Rio de Janeiro, Brasil.

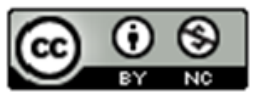

This work is licensed under a Creative Commons Attribution-NonCommercial 4.0 International (CC BY-NC 4.0) 